\title{
Effects of vitamin $C$ supplementation on the glycemic control and cardiovascular risk in Type II Diabetes Mellitus
}

\author{
Praveen DEVANANDAN 1 (D), Ranadheer Chowdary PUVVADA ${ }^{2}(\mathbb{D})$, Vijey Aanandhi MUTHUKUMAR ${ }^{3}$ \\ $*$ (iD) \\ 1 Research Scholar, School of Pharmaceutical Sciences, Vels Institute of Science, Technology \& Advanced Studies \\ (VISTAS), Chennai, Tamilnadu, India. \\ 2 Research Scholar, School of Pharmaceutical Sciences, Vels Institute of Science, Technology \& Advanced Studies \\ (VISTAS), Chennai, Tamilnadu, India. \\ 3 Department of Pharmaceutical Chemistry and Analysis, School of Pharmaceutical Sciences, Vels Institute of Science, \\ Technology \& Advanced Studies (VISTAS), Chennai, Tamil Nadu, India. \\ * Corresponding Author. E mail: hodpchemistry@velsuniv.ac.in (V.A.M.); Tel. +91-984-095 9519.
}

Received: 09 August 2019 / Revised: 31 January 2020 / Accepted: 03 February 2020

\begin{abstract}
The oral hypoglycaemic agents as well as injectable insulin does not significantly alter the oxidative stress in the diabetes mellitus patients. Being an antioxidant Vitamin C (ascorbic acid) might help in tackling the adversities of reactive oxygen species. A randomized placebo controlled study was carried out with parallel assignment of both the test group and control group of patients. The intervention model included metformin $500 \mathrm{mg}$ twice daily and a placebo once daily for control group. Alternatively, Vitamin C chewable tablets were given for the other group along with metformin $500 \mathrm{mg}$ twice daily. Our study postulates that there is a significant reduction in the fasting blood glucose, glycosylated haemoglobin levels, troponin $\mathrm{T}$ levels and Framingham risk score in participants who received ascorbic acid supplementation along with regular metformin. The supplementation of Vitamin $C$ along with Metformin was well tolerated and did not cause any serious adverse drug reactions. The cheaper cost adjuvant approach with Vitamin $\mathrm{C}$ may be beneficial in patients in reducing the cardiovascular risk as well as to maintain an appropriate glycaemic control
\end{abstract}

KEYWORDS: Diabetes Mellitus; ascorbic acid; glycemic control; cardiovascular risk.

\section{INTRODUCTION}

Diabetes Mellitus is one of the most important metabolic disorder affecting the mankind characterised not only by hyperglycemia but also by other factors such as insulin resistance by the cells and tissues and marked oxidative stress [1]. There are several research studies that emphasized on the free radical effects in Diabetes Mellitus. The available oral hypoglycaemic agents as well as insulin does not significantly alter the oxidative stress in the diabetic patients. Being an antioxidant Vitamin $\mathrm{C}$ might help in tackling these complications by scavenging the reactive oxygen species [2]. Furthermore, Vitamin C may play a significant role in the prevention of non- enzymatic protein glycosylation [3]. Vitamin $C$ enhances the formation of Lipoxin A4, Prostaglandin E1 which are potent antioxidants [4].

The available literature suggests conflicting outcomes in ascorbic acid supplementation in diabetic patients. There are really very few studies that studied the effects of Vitamin C with a fixed drug, for instance metformin, on glycaemic control parameters as well as on the cardiovascular risk parameters in type II diabetes mellitus. However, most studies on this area suggested a randomized study design to effectively analyse these specific outcomes $[5,6]$.

\section{RESULTS}

The scheme of patients included for the study is given in trial profile (Figure 1).

How to cite this article: Devanandan P, Puvvada RC, Muthukumar VA. Effects of vitamin C supplementation on the glycemic control and cardiovascular risk in Type II Diabetes Mellitus. J Res Pharm. 2020; 24(2): 182-187. 


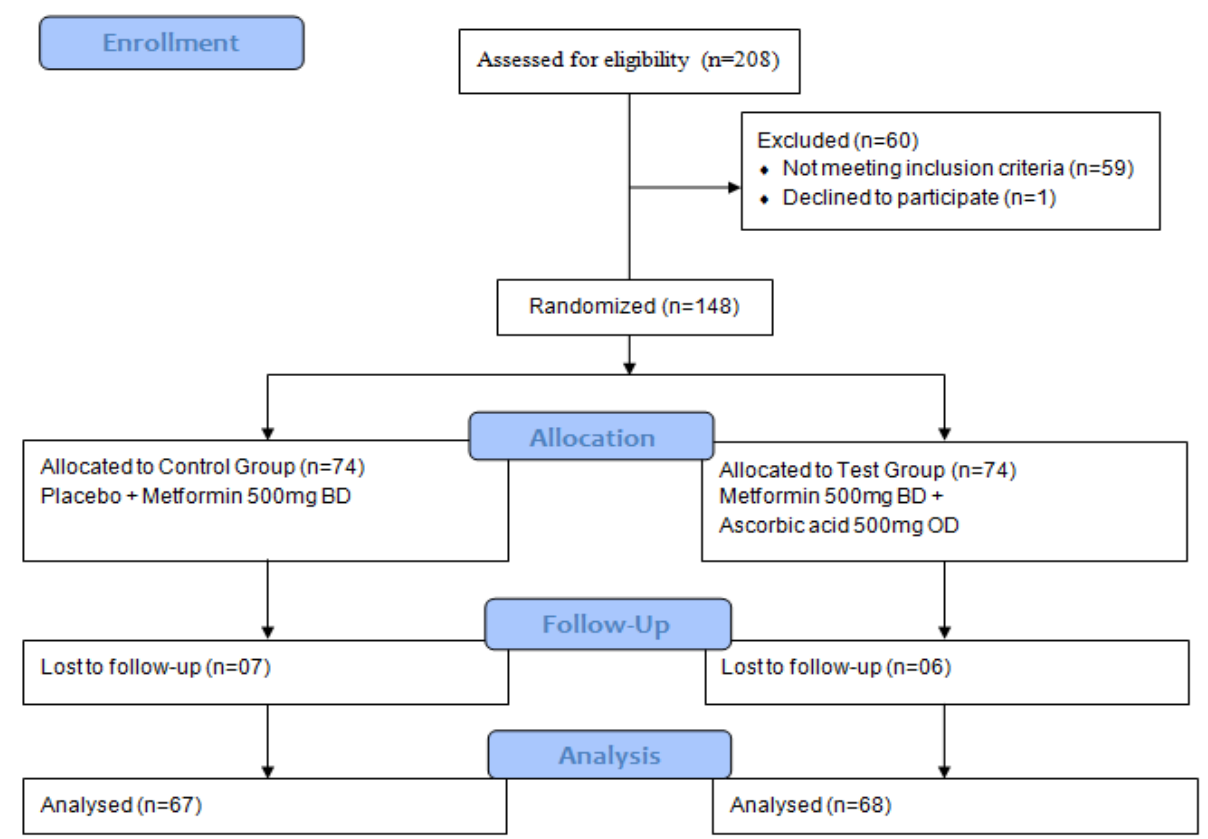

Figure 1. Trial profile.

Table 1. Baseline parameters of study participants.

\begin{tabular}{|c|c|c|c|c|}
\hline S.No & Characteristics & Control $(n=67)$ & Trial $(n=68)$ & P value \\
\hline 01 & Age in yrs (mean \pm SEM) & $41.6 \pm 8.2$ & $48.2 \pm 7.2$ & 0.5231 \\
\hline 02 & Male $(n=84)$ & 47 & 37 & 0.6612 \\
\hline 03 & Duration of Diabetes in yrs (mean \pm SEM) & $3.2 \pm 0.9$ & $3.5 \pm 0.5$ & 0.7715 \\
\hline 04 & Family History $(\mathrm{n}=67)$ & 35 & 32 & 0.7214 \\
\hline 05 & BMI (mean $\pm S E M)$ & $24.3 \pm 0.5$ & $23.2 \pm 0.9$ & 0.2886 \\
\hline 06 & $\operatorname{HTN}(n=36)$ & 20 & 16 & 0.6241 \\
\hline 07 & Dyslipidemia $(n=0)$ & 0 & 0 & 1.0000 \\
\hline 08 & Bronchial Asthma $(n=2)$ & 1 & 1 & 1.0000 \\
\hline 09 & Sr.Vitamin C Levels mg/dL(mean \pm SEM) & $0.54 \pm 0.16$ & $0.49 \pm 0.13$ & 0.8090 \\
\hline
\end{tabular}

BMI-Body Mass Index, HTN - Hypertension

All values are Mean \pm SEM unless otherwise mentioned. ${ }^{*} p<0.05$ is considered significant

Table 1 includes the baseline parameters of the selected participants in the study. It could be seen that there is no significant difference between both the groups during the initial screening.

Table 2. Fasting blood glucose levels.

\begin{tabular}{lcccc}
\hline $\begin{array}{l}\text { Fasting Blood Glucose Levels } \\
(\mathbf{m g} / \mathrm{dL})\end{array}$ & $\mathbf{0}^{\text {th }}$ Month & 3 $^{\text {rd }}$ Month & $\mathbf{6}^{\text {th }}$ Month & $\mathbf{9}^{\text {th }}$ Month \\
\hline Control $(\mathrm{n}=67)$ & $182.2 \pm 4.1$ & $175.1 \pm 7.6$ & $167.4 \pm 6.2$ & $159.3 \pm 5.1$ \\
Trial $(\mathrm{n}=68)$ & $187.3 \pm 4.2$ & $169.2 \pm 3.7^{*}$ & $157.7 \pm 3.0^{*}$ & $144.6 \pm 5.4^{*}$ \\
\hline
\end{tabular}

All values are Mean \pm SEM.* $\mathrm{p}<0.05$ is considered significant. 
On performing the analysis of variance followed by a post-hoc analyses, it was found out that trial arm had a significant reduction in the fasting blood glucose levels $(p=0.0032)$.

Table 3. $\mathrm{HbA}_{1} \mathrm{C}$ levels.

\begin{tabular}{lcccc}
\hline HbA1C levels (\%) & 0 $^{\text {th }}$ Month & $3^{\text {rd }}$ Month & $\begin{array}{c}\mathbf{6}^{\text {th }} \\
\text { Month }\end{array}$ & 9 $^{\text {th }}$ Month \\
\hline Control $(\mathrm{n}=67)$ & $9.7 \pm 0.2$ & $9.4 \pm 0.6$ & $8.9 \pm 1.2$ & $8.3 \pm 1.1$ \\
Trial $(\mathrm{n}=68)$ & $9.6 \pm 0.3$ & $8.4 \pm 0.7^{*}$ & $7.7 \pm 0.3^{*}$ & $6.9 \pm 0.4^{*}$ \\
\hline
\end{tabular}

All values are Mean \pm SEM. ${ }^{*} p<0.05$ is considered significant.

On performing the analysis of variance followed by a post-hoc analyses, it was found out that trial arm had a significant reduction in the $\mathrm{HbA}_{1} \mathrm{C}$ levels $(\mathrm{p}=0.0083)$.

Table 4. Troponin T levels.

\begin{tabular}{lcccc}
\hline $\begin{array}{l}\text { Troponin T levels } \\
(\mathbf{n g} / \mathrm{L})\end{array}$ & $\mathbf{0}^{\text {th }}$ Month & $\mathbf{3}^{\text {rd }}$ Month & $\mathbf{6}^{\text {th }}$ Month & $9^{\text {th }}$ Month \\
\hline Control $(\mathrm{n}=67)$ & $12.2 \pm 2.1$ & $12.1 \pm 1.6$ & $12.7 \pm 1.5$ & $12.3 \pm 1.1$ \\
Trial $(\mathrm{n}=68)$ & $12.3 \pm 1.2$ & $11.2 \pm 1.7^{*}$ & $9.7 \pm 1.0^{*}$ & $8.6 \pm 0.4^{*}$ \\
\hline
\end{tabular}

All values are Mean \pm SEM. ${ }^{*} p<0.05$ is considered significant.

On performing the analysis of variance, it was found out that trial arm had a significant reduction in the Troponin T levels $(\mathrm{p}=0.0495)$

Table 5. Framingham risk assessment score.

\begin{tabular}{lcccc}
\hline Framingham Risk Score & $0^{\text {th }}$ Month & $\begin{array}{c}3^{\text {rd }} \\
\text { Month }\end{array}$ & $\mathbf{6}^{\text {th }}$ Month & $\mathbf{9}^{\text {th }}$ Month \\
& \multicolumn{5}{c}{} \\
\hline Control $(\mathrm{n}=67)$ & $17.7 \pm 1.2$ & $17.4 \pm 0.9$ & $16.9 \pm 1.1$ & $16.3 \pm 2.1$ \\
Trial $(\mathrm{n}=68)$ & $19.6 \pm 1.3$ & $16.4 \pm 1.7$ & $15.7 \pm 1.3^{*}$ & $13.9 \pm 2.4^{*}$ \\
\hline
\end{tabular}

All values are Mean \pm SEM.* $p<0.05$ is considered significant.

Table 5 indicates Framingham risk assessment that is a Canadian risk assessment scale for predicting the cardiovascular risk. On performing the analysis of variance, it was found out that trial arm had a significant reduction in the Framingham Risk assessment $(\mathrm{p}=0.0312)$.

Table 6.Serum vitamin C levels.

\begin{tabular}{lcccc}
\hline Serum Vitamin C $(\mathbf{m g} / \mathbf{d L})$ & $0^{\text {th }}$ Month & $\begin{array}{c}3^{\text {rd }} \\
\text { Month }\end{array}$ & $\mathbf{6}^{\text {th }}$ Month & $\mathbf{9}^{\text {th }}$ Month \\
& \multicolumn{5}{c}{} \\
\hline Control $(\mathrm{n}=67)$ & $0.54 \pm 0.16$ & $0.51 \pm 0.19$ & $0.59 \pm 0.25$ & $0.53 \pm 0.16$ \\
Trial $(\mathrm{n}=68)$ & $0.49 \pm 0.13$ & $0.74 \pm 0.11^{*}$ & $0.87 \pm 0.16^{*}$ & $1.01 \pm 0.23^{*}$ \\
\hline
\end{tabular}

All values are Mean \pm SEM. ${ }^{*} \mathrm{p}<0.05$ is considered significant.

On performing the analysis of variance, it was found out that trial arm had a significant reduction in the Serum Vitamin C levels ( $p=0.0002)$. Not a single case of hypervitaminosis reported during the entire Study. 


\section{DISCUSSION}

Our study postulates that there is a significant reduction in the fasting blood glucose, glycosylated haemoglobin levels, troponin $\mathrm{T}$ levels and Framingham risk score in participants who received ascorbic acid supplementation along with regular metformin. Although we had lost few patients to follow up, we were able to achieve a target sample size throughout the course of the study. The significant reduction in fasting blood glucose levels (Table 2) agrees with the report published by Girgis C et al 2015 [7]. Similarly Kostisawat J et al had reported that Vitamin C might help in reduction of glycated haemoglobin levels in Diabetes patients [8]. In our study, the glycated haemoglobin levels of the trial participants significantly reduced from the 3rd Month evaluation. Our results contradicts with the results published by McSorley PT et al is significantly reducing Troponin $\mathrm{T}$ levels [9]. Framingham risk score is significantly reduced predominantly due to reduction in systolic blood pressure, which is an integral parameter in assessing Framingham Risk score. This results correlates with the study published by Mason SA et al [10].

Multiple pathways such as oxidation of glucose, Polyol pathway, non-enzymatic Glycosylation of proteins may contribute to the increased release of free radical [11-13]. The effects of such reactive oxygen species may be overcome by administering the patients with an antioxidant such as ascorbic acid. It was clearly evident from the initial screening that most of the diabetic patients had vitamin $C$ deficiency. Hence, they are in a dire necessity to receive ascorbic acid. The improvement in the Serum Vitamin $C$ status of trial group has been observed from the 3rd month itself. The Vitamin $C$ status gradually increased in the normal range between $0.6 \mathrm{mg} / \mathrm{dL}$ and $1.2 \mathrm{mg} / \mathrm{dL}$ during this period. Thus forth, there is no case of hypervitaminosis being reported (Fig 5). This may probably due to the water soluble nature of vitamin C [14]. The supplementation of vitamin $\mathrm{C}$ would have reduced the ameliorating cardiovascular risk in diabetic patients. The significant improvement in the glycaemic control status maybe correlated with antioxidant effects onbeta cells [15]. Hence other antioxidant micronutrients such as vitamin E could also be beneficial. Furthermore, an evaluative study on the pharmacokinetic interaction between metformin and vitamin C could help us understand the basis of this outcome [16].

No serious Adverse Drug Reaction (ADR) is reported in the study. All the patients were closely monitored by a team of general physicians, endocrinologist, dietician and other health care workers throughout the study. The limitation of this study is the small sample size which could be analysed and improved in the future studies.

\section{CONCLUSION}

The supplementation of ascorbic acid along with metformin was well tolerated and improved the glycemic status significantly. Also, the cardiovascular risk significantly reduced in the patients who received ascorbic acid supplementation. Furthermore, it did not cause any serious Adverse Drug Reaction. The cheaper cost adjuvant approach with vitamin $\mathrm{C}$ may be beneficial for adequate glycemic control and cardiovascular risk reduction in diabetic patients. However we recommend for a large scale study in the near future.

\section{MATERIALS AND METHODS}

\subsection{Study design}

A randomized placebo-controlled study was carried out in the general medicine department of a tertiary care teaching hospital with parallel assignment of both the test group and control group of patients. Per-protocol analysis was followed in the selection of the patients. Randomized permuted blocks method was used in randomly allocating the patients. This allocation sequence was derived from an online randomization generator [17]. The primary endpoint is the safety and efficacy analysis.

\subsection{Patient selection}

Initially 208 patients were interested to take part in our study. We allocated patients only if they suitably qualify the Inclusion and Exclusion criteria. All the patients above 18 years of age who are diagnosed with type II diabetes mellitus and taking metformin alone were included. Patients having fasting blood glucose level in the range of 126 to $250 \mathrm{mg} / \mathrm{dL}$ and $\mathrm{HbA1C}$ in the range of $7.0-9.9 \%$ were included.

Individuals unable to give informed consent, those with a medical history of significant gastrointestinal disease e.g. inflammatory bowel disease, those who had undergone a previous bowel resection, individuals taking diabetes medication other than metformin were excluded from the study. Routine investigations like electrocardiogram, serum electrolytes, blood urea, creatinine and liver function tests were performed to 
exclude active medical problems in all patients. The study was approved by the Institutional Ethics Committee VISTAS-SPS/IEC/2018/I/07. Informed consent has been obtained from all the participants of the study.

\subsection{Sample size and treatment arms}

Sample size was derived based on the previous literature and population size of 500 (Prevalence rate at the study site in the previous year), the sample size was estimated to be atleast 139 . The intervention model included metformin 500mg twice daily and a placebo once daily for control group. Alternatively, ascorbic acid $500 \mathrm{mg}$ chewable tablets were given for the other group along with metformin 500mg twice daily. All the participating patients were advised on their usual diet plans limiting the consumption of Vitamin C rich foods. Each patient was counselled by a dietician on the diet to be followed. Initially, all the patients were evaluated for parameters such as serum vitamin C levels, Fasting Blood Glucose levels, $\mathrm{HbA1C}$, troponin T, lipid profile, etc. The same parameters was repeated every 3 months until the $9^{\text {th }}$ month end. Necessary auto-analysers were used for evaluation of each of these parameters. The medication adherence was evaluated using the traditional pill count method.

\subsection{Statistical analysis}

All parametric data expressed in mean \pm SEM (Standard Error of Mean). The Efficacy analysis would be carried out with the help of Analysis of Variance with a 95\% level of significance. ' $\mathrm{P}$ ' Value less than 0.05 is considered significant. All statistical analysis were performed using Graph Pad prism software.

Acknowledgements: The authors are very thankful to Vels Institute of Science Technology and Advanced Studies (VISTAS) and its management for providing research facilities and encouragement.

Author Contributions: Concept - P.D., R.C.P., M.V.A.; Design - P.D., R.C.P., M.V.A.; Supervision - M.V.A.; Materials - P.D., R.C.P., M.V.A; Data Collection and/or Processing - P.D., R.C.P., M.V.A.; Analysis and/or Interpretation - P.D., R.C.P, M.V.A.; Literature Search - P.D., R.C.P., M.V.A.; Writing - P.D., R.C.P., M.V.A.; Critical Reviews - P.D., R.C.P., M.V.A.

Conflict of interest statement: The authors declared no conflict of interest.

Ethics committee approval: The study was approved by the Institutional Ethics Committee VISTAS-SPS/IEC/2018/I/07. Informed consent has been obtained from all the participants of the study.

\section{REFERENCES}

[1] Mazloom Z, Hejazi N, Dabbaghmanesh M.H, Tabatabaei H.R, Ahmadi A, Ansar H. Effect of vitamin C supplementation on postprandial oxidative stress and lipid profile in type 2 diabetic patients. Pak J Biol Sci. 2011; 14(19): 900-904. [CrossRef]

[2] Prajapat R, Bhattacharya I. Effect of Vitamin E and C Supplementation on Oxidative Stress in Diabetic Patients. Adv Diabet Metabol. 2017; 5(3): 39-42. [CrossRef]

[3] Alamdari DH, Paletas K, Pegiou T, Sarigianni M, Befani C, Koliakos GA. A novel assay for the evaluation of the prooxidant-antioxidant balance, before and after antioxidant vitamin administration in type II diabetes patients. Clin Biochem. 2007; 40(3): 248-254. [CrossRef]

[4] Das, U. Vitamin C for Type 2 Diabetes Mellitus and Hypertension. Arch Med Res. 2019; 50(2): 11-14. [CrossRef]

[5] Bianchi C, Miccoli R, Daniele G, Penno G, Del Prato S. Is there evidence that oral hypoglycemic agents reduce cardiovascular morbidity/mortality? yes. Diabet care. 2009; 32(2): 342-348. [CrossRef]

[6] Bishop N, Schorah CJ, Wales JK. The effect of vitamin C supplementation on diabetic hyperlipidaemia: a double blind, crossover study. Diabet Med. 1985; 2(2): 121-124. [CrossRef]

[7] Girgis C, Christie-David D, Gunton J. Effects of vitamins C and D in type 2 diabetes mellitus. Nutr Diet Suppl. 2015; 7: 21-28. [CrossRef]

[8] Kositsawat J, Freeman VL. Vitamin C and A1c relationship in the National Health and Nutrition Examination Survey (NHANES) 2003-2006. J Am Coll Nutr. 2011; 30: 477-483. [CrossRef]

[9] McSorley PT, Bell PM, Young IS, Atkinson AB, Sheridan B, Fee JP, et al. Endothelial function, insulin action and cardiovascular risk factors in young healthy adult offspring of parents with type 2 diabetes: effect of vitamin $C$ in a randomized double-blind, controlled clinical trial. Diabet Med. 2015; 22: 703-710. [CrossRef] 
[10] Mason SA, Rasmussen B, van Loon L, Salmon J, Wadley G. Ascorbic acid supplementation improves postprandial glycaemic control and blood pressure in individuals with type 2 diabetes: Findings of a randomized cross-over trial. Diab Obes Metab. 2018; 21(3): 674-682. [CrossRef]

[11] Zatalia SR, Sanusi H. The role of antioxidants in the pathophysiology, complications, and management of diabetes mellitus. Acta Med. Indones. 2013; 45(2): 141-147.

[12] Xu R, Zhang S, Tao A, Chen G, Zhang M. Influence of Vitamin E Supplementation on Glycaemic Control: A MetaAnalysis of Randomised Controlled Trials. PLoS ONE. 2014; 9(4): e95008. [CrossRef]

[13] Wilson R, Willis J, Gearry R, Skidmore P, Fleming E, Frampton C et al. Inadequate Vitamin C Status in Prediabetes and Type 2 Diabetes Mellitus: Associations with Glycaemic Control, Obesity, and Smoking. Nutrients. 2017; $9(9): 997$. [CrossRef]

[14] Srivatsan R, Das S, Gadde R, et al. Antioxidants and lipid peroxidation status in diabetic patients with and without complications. Arch Iran Med. 2009; 12(2): 121-127.

[15] Davie SJ, Gould BJ, Yudkin JS. Effect of vitamin C on glycosylation of proteins. Diabetes. 1992; 41(2): 167-173. [CrossRef]

[16] Eriksson J, Kohvakka A. Magnesium and ascorbic acid supplementation in diabetes mellitus. Ann Nutr Metab. 1995; 39(4): 217-223. [CrossRef]

[17] Sealed Envelope Ltd. 2018. Create a blocked randomisation list. [Online] Available from: https://www.sealedenvelope.com/simple-randomiser/v1/lists [Accessed on 15 Apr 2018].

This is an open access article which is publicly available on our journal's website under Institutional Repository at http://dspace.marmara.edu.tr. 